\title{
Effects of Composite Porous Gas-Diffusion Layers on Performance of Proton Exchange Membrane Fuel Cell
}

\author{
Taqi Ahmad Cheema', Gyu Man Kim', Choon Young Lee', Moon Kyu Kwak', \\ Hyoung Bum Kim², and Cheol Woo Park, \\ 1 School of Mechanical Engineering, Kyungpook National University, 1370 Sankyuk-dong, Buk-gu, Deagu, South Korea, 702-701 \\ 2 School of Mechanical Engineering, Gyeongsang National University, Jinju, South Korea, 660-701 \\ \# Corresponding Author / E-mail: chwoopark@knu.ac.kr, TEL: +82-53-950-7569, FAX: +82-53-950-6550
}

KEYWORDS: Gas diffusion layer, Fuel cell, Porosity, Positional variation, Mass transport

\begin{abstract}
The gas diffusion layer (GDL) is an important component of proton-exchange membrane fuel cells (PEMFCs) that participate in the interplay of the transport of different species. During the assembly of PEMFCs, mechanical pressure is applied to the solid boundary of bipolar plates to reduce the porosity of the adjacent $G D L$, especially under land areas. This variation in porosity reduces reactant consumption in the catalyst layer and primarily causes non-uniform current density in PEMFCs. To compensate for the loss of porosity in the GDL, a composite porous diffusion layer was used as a GDL with higher porosity in the under-land areas of the GDL than that in the under-channel areas. A numerical simulation was conducted to investigate the effect of the positional variation of porosity on the performance of the PEMFC. The overall performance of the cell was investigated through a polarization plot, and the local mass transport of the reactant species was evaluated at the two reaction sites. The introduction of the proposed composite porous GDL improved the performance of the PEMFC by enhancing the transport of the reactant species to and from the reaction site.
\end{abstract}

\section{NOMENCLATURE}

$\mathrm{C}_{\mathrm{H}_{2}}=$ local hydrogen concentration $\left(\mathrm{mol}-\mathrm{m}^{-3}\right)$

$\mathrm{C}_{\mathrm{H}_{2}}^{\mathrm{ref}}=$ reference hydrogen concentration $\left(\mathrm{mol}-\mathrm{m}^{-3}\right)$

$\mathrm{C}_{\mathrm{O}_{2}}=$ local oxygen concentration $\left(\mathrm{mol}-\mathrm{m}^{-3}\right)$

$\mathrm{C}_{\mathrm{O}_{2}}^{\mathrm{ref}}=$ reference oxygen concentration $\left(\mathrm{mol}-\mathrm{m}^{-3}\right)$

$\mathrm{i}_{0, \mathrm{a}}^{\mathrm{ref}}=$ anode reference exchange current density $\left(\mathrm{A}-\mathrm{m}^{-3}\right)$

$\mathrm{i}_{0, \mathrm{c}}^{\mathrm{ref}}=$ cathode reference exchange current density $\left(\mathrm{A}-\mathrm{m}^{-3}\right)$

$\mathrm{p}=$ pressure of fluid $(\mathrm{Pa})$

$\overrightarrow{\mathrm{u}}=$ fluid velocity vector $(\mathrm{m} / \mathrm{s})$

$\vec{i}=$ current density $\left(\mathrm{A} / \mathrm{m}^{2}\right)$

$\mathrm{R}_{\text {cell }}=$ cell resistance $(\Omega)$

$\mathrm{k}_{\mathrm{p}}=$ hydraulic permeability $\left(\mathrm{m}^{2}\right)$

$\mathrm{F}=$ Faraday's constant $(\mathrm{C} / \mathrm{mol})$

$\mathrm{T}=$ temperature of cell $(\mathrm{K})$

$\mathrm{V}_{\text {cell }}=$ cell operating potential $(\mathrm{V})$

\footnotetext{
$\mathrm{V}_{\text {rev }}=$ reversible cell potential $(\mathrm{V})$

$\rho=$ density of fluid $\left(\mathrm{kg} / \mathrm{m}^{3}\right)$

$\mu=$ viscosity of fluid (Pa-s)

$\varepsilon=$ porosity

$\xi=$ stoichiometric flow ratio

$\mathrm{D}=$ diffusion coefficient $\left(\mathrm{m}^{2} \mathrm{~s}^{-1}\right)$

$\tau=$ tortuosity of the porous media

$\eta=$ overpotential

$\sigma_{\mathrm{m}}=$ membrane protonic conductivity $\left(\mathrm{Sm}^{-1}\right)$

$\sigma_{\mathrm{g}}=$ electronic conductivity of GDL $\left(\mathrm{Sm}^{-1}\right)$
}

\section{Introduction}

Fuel cells are electrochemical devices that directly convert chemical energy into electrical energy. The production of electricity in the absence of moving parts and of burning fuel makes fuel cells environment-friendly and a suitable power system for terrestrial and space applications. Proton- 
exchange membrane fuel cells (PEMFCs) stand out as the most attractive among all fuel cells because of their solid polymer electrolytes, low operating temperature, miniature structure and quick startup and shutdown facilities. The overall performance of the PEMFC is governed by the complicated transport of reactants, products, charge and heat. The gas diffusion layer (GDL) is an important component of a PEMFC to participate in the interplay of transport of various species. The functional requirement of GDL greatly depends on morphological, thermal, electric and mechanical properties, such as porosity, thermal and electric conductivity and chemical and physical durability, as reported by Mathias et al.. ${ }^{1}$

GDL is generally made up of carbon cloth and paper coated with polytetrafluoroethylene. In the assembly process, which seals the fuel cell, the application of compression pressure changes the morphology of the diffusion layer. The thickness and porosity of the soft and flexible material of the GDL layer under compression pressure vary. Liquid water in the GDL is another source of porosity variation, which was first observed by Gurau et al. when they developed a one-dimensional halfcell model. ${ }^{2}$ At high current densities, the liquid water generated on the cathode side may block GDL pores and affect overall cell performance.

Non-uniform porosity in the GDL reduces the overall reactant flux at the catalyst layer, particularly under the landing areas of the bipolar plate. As a result, current distribution in the electrode is also nonuniform. Therefore, some catalyst particles remain unreacted in the catalyst layer, especially under the landing areas of the bipolar plates. The catalyst layer has previously been modeled as a continuum interface between the membrane and GDL and as an agglomerate model consisting of agglomerate particles. ${ }^{3-6}$

Many experimental studies have considered the effects of porosity variation as a function of compression pressure on fuel cell performance. ${ }^{7-9}$ The high operating cost has made fuel cell experiments difficult to perform. Thus, numerical modeling has become an effective alternative to such experiments in academic research. Many mathematical modeling studies have used constant GDL porosity; however, this assumption fails to approximate the physical attribute of GDL in the fuel cell. ${ }^{10-12}$ The concept of non-uniform porosity was introduced by Chu et al., who investigated its effect on fuel cell performance. ${ }^{13}$ They used four different continuous functions of positions with different porosity values. Roshandel et al. used a porosity variation function of the form $\sin ^{2 n}(x)$ on the $2 \mathrm{D}$ model of Stockie et al.. ${ }^{5,14,15}$ However, Roshandel et al. neglected the effects of GDL thickness, which should not be ignored being an important influential factor in the PEMFC overall performance as was reported by Inamuddin et al.. ${ }^{16}$

Considering the loss of GDL porosity due to application of mechanical pressure, this study aims to address this concern by proposing a composite porous layer having an initially higher porosity under land areas than under channel areas. The increased porosity will compensate the porosity loss when the mechanical pressure is applied during assembly keeping the effective porosity of GDL unaffected. Therefore, the present study aims to improve PEMFC performance by compensating for the loss of porosity without a significant increase in the manufacturing cost. Accordingly, a new method for the positional variation of GDL porosity is proposed to enhance flow and mass transfer properties with higher porosity under the land area than that under the channel area. This method counters the effects of reduced porosity and thus affects overall PEMFC performance. A numerical simulation is performed to investigate PEMFC performance by using the composite GDL porous layer. A 3D PEMFC along the channel model is used, and the multi-physics of flow, porous media, chemical reactions and charge transfer are coupled and solved simultaneously. Many researchers have employed Darcy's law to solve the physics of porous media without considering the viscous effects; therefore, the actual physical situation inside a PEMFC cannot be exactly predicted. ${ }^{17}$ Therefore, we make use of the Brinkman equation to incorporate the viscous effects in the proposed composite porous GDL. The performance of the PEMFC is evaluated by computing the polarization curves and mass transfer characteristics for different values of porosity in the GDL.

\section{Model Development and Mathematical Modeling}

Fig. 1 shows the 3D along-the-channel PEMFC model (length= $0.05 \mathrm{~m}$ ) used in the simulation. This model consists of 11 components with two parallel flow channels on each side of anode and cathode. Graphite bipolar plates surround the two channels and are directly attached to the GDL to collect current. The proton exchange membrane is the central part of the model. Two catalyst layers serve as reaction sites on each side of the membrane.

\subsection{Model Assumptions}

The model works on the following assumptions:

I. The cell operates at a steady state and in isothermal conditions.

II. Ideal gas for all species and laminar and incompressible flow is considered.

III. No deformation occurs in any part of the cell.

IV. The membrane is almost completely impermeable, with low permeability values for gas transport.

V. Isotropic and homogenous electrolyte, electrode and bipolar plate materials.

Additional assumptions required to model transport in the cell are subsequently discussed.

\subsection{Governing Equations}

Flow in the gas channel is governed by continuity (1), momentum (2) and mass transport (3):

$$
\nabla \cdot(\rho u)=0,
$$

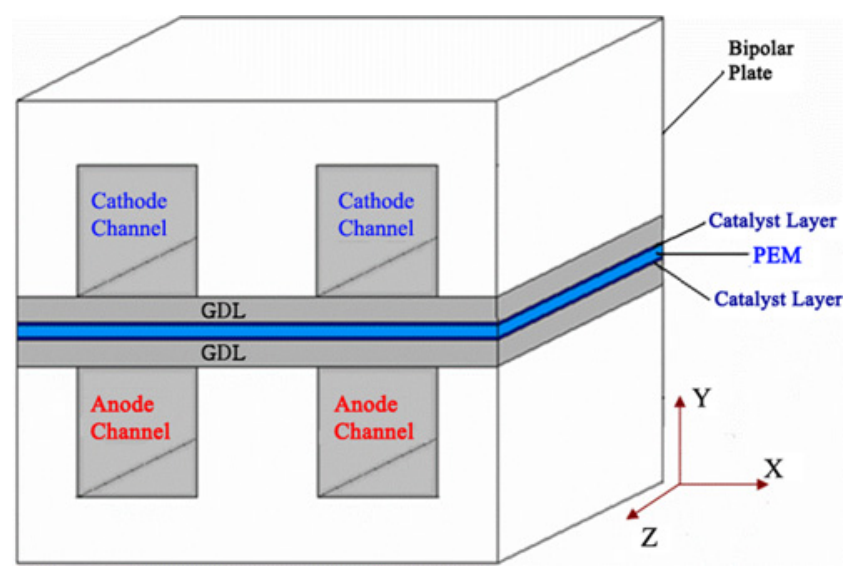

Fig. 1 Computational model used in the study 


$$
\begin{gathered}
\nabla \cdot(\rho u \cdot u-\mu \nabla u)=-\nabla\left(p+\frac{2}{3} \mu \nabla \cdot u\right)+\nabla \cdot\left[\mu(\nabla u)^{T}\right], \\
\nabla .\left(\rho u Y_{i}\right)-\nabla \cdot\left(\rho D_{i i} \nabla Y_{i}\right)=\nabla \cdot\left(\rho D_{i j} \nabla Y_{j}\right),
\end{gathered}
$$

where subscript $i$ denotes the oxygen or hydrogen species, $j$ represents water vapor on both sides, and $D_{i i}$ and $D_{i j}$ are the Stefan-Maxwell ternary diffusion coefficients obtained from Taylor and Krishna multicomponent mass transfer. ${ }^{18}$

\subsubsection{GDL Modeling}

The purpose of GDL is not only to facilitate the flow of reactants into the reaction site but also to serve as an electrical bridge between the catalyst layer and bipolar plates. GDL drives away the water produced from the cell and protects the thin catalyst layer. Transport phenomenon in the GDL is explained by the following equations:

Continuity equation for porous media:

$$
\nabla \cdot(\rho \varepsilon u)=0
$$

The momentum equation for porous media is given by the Brinkman equation:

$$
\frac{\mu}{k} \vec{V}=-\nabla p+\mu \nabla\left(\nabla \vec{u}+(\nabla \vec{u})^{T}\right)
$$

Transport equation for porous media:

$$
\nabla \cdot\left(\rho \varepsilon u Y_{i}\right)-\nabla \cdot\left(\rho \varepsilon D_{i i} \nabla Y_{i}\right)=\nabla \cdot\left(\rho \varepsilon D_{i j} \nabla Y_{j}\right)
$$

The effective mass diffusivity coefficient is related to porosity via the Bruggemann relation:

$$
D_{i j}^{e f f}=D_{i j} \times \varepsilon^{\tau}
$$

The empirical exponent $\tau$ is usually taken as 1.5 times the tortuosity for a given porosity. The potential distribution in the GDL is given as a source term:

$$
\nabla \cdot\left(\sigma_{g} \nabla \phi\right)=S_{e},
$$

\subsubsection{Membrane Modeling}

Water balance is governed by the net water flux through the membrane:

$$
N_{w}=\eta_{d} M_{H_{2}} O \frac{i}{F}-\nabla \cdot\left(\rho D_{w} \nabla Y_{w}\right)
$$

where $\eta_{d}$ is the electro-osmotic drag coefficient and $D_{w}$ is the water diffusion coefficient in the membrane. Potential loss due to resistance to proton transport in the membrane is given as a source term:

$$
\nabla \cdot\left(\sigma_{m} \nabla \phi\right)=S_{m}
$$

where $\sigma_{\mathrm{m}}$ is the membrane's protonic conductivity, which can be calculated by the relation given by Springer et al.: ${ }^{19}$

$$
\sigma_{m}(T)=\sigma_{m}^{r e f} \exp \left[1268\left(\frac{1}{303}-\frac{1}{T}\right)\right]
$$

The reference protonic conductivity of the membrane is

$$
\sigma_{m}^{r e f}=0.005139 \lambda-0.00326
$$

where,

$$
\lambda=\left\{\begin{array}{c}
0.043+17.81 a-39.85 a^{2}+36.0 a^{3} \quad 0 \leq a=\frac{P_{\text {sat }}}{P} \leq 1 \\
14+1.4(a-1) \quad 1 \leq a \leq 3
\end{array}\right.
$$

where $a$ is the activity of water vapor at the cathode side and $\mathrm{P}_{\text {sat }}$ is the water's saturation pressure, which can be expressed as:

$$
P_{\text {sat }}=-2.1794+0.02953 T-9.1837 \times 10^{-5} T^{2}+1.4454 \times 10^{-7} T^{3}
$$

\subsubsection{Electrochemical Reaction Kinetics}

Reactants are consumed at the catalyst layers to produce water and heat. This consumption is modeled as source and sink terms. At the anode catalyst layer, hydrogen is consumed to produce electrons and protons. The rate of hydrogen consumption is given by

$$
S_{H_{2}}=-\frac{M_{H_{2}}}{2 F} i_{a}
$$

Similarly, the rate of oxygen consumption at the cathode-side catalyst layer is

$$
S_{\mathrm{O}_{2}}=-\frac{M_{\mathrm{O}_{2}}}{2 F} i_{c}
$$

The produced water can be described as a source term based on the local current density of the cathode:

$$
S_{\mathrm{H}_{2} \mathrm{O}}=-\frac{M_{\mathrm{H}_{2} \mathrm{O}} \mathrm{O}}{2 \mathrm{~F}} i_{c}
$$

The local current density can be calculated according to Butler-Volmer equation:

$$
\begin{aligned}
& i_{a}=i_{0, a}^{r e f}\left(\frac{C_{H_{2}}}{C_{H_{2}}^{r e f}}\right)^{\gamma H_{2}}\left[\exp \left(\frac{\alpha_{a} F}{R T} \eta_{a c t, a}\right)-\exp \left(\frac{\alpha_{c} F}{R T} \eta_{a c t, a}\right)\right], \\
& i_{c}=i_{0, c}^{r e f}\left(\frac{C_{O_{2}}}{C_{O_{2}}^{r e f}}\right)^{\gamma O_{2}}\left[\exp \left(\frac{\alpha_{a} F}{R T} \eta_{a c t, c}\right)-\exp \left(\frac{\alpha_{c} F}{R T} \eta_{a c t, c}\right)\right],
\end{aligned}
$$

$\alpha_{a}$ and $\alpha_{c}$ are the anode and cathode charge transfer coefficients respectively; and $\gamma$ is the empirical concentration parameter.

The activation over potential is calculated as

$$
\eta_{a c t}=\frac{R T}{2 \alpha F} \ln \left(\frac{i}{i_{0}}\right)
$$

The ohmic and protonic overpotentials, the main causes of the performance drop in a fuel cell at medium current density, can be calculated by the following equations:

$$
\begin{aligned}
& \eta_{o h m, g}=\frac{I}{\sigma_{g}} l_{g}, \\
& \eta_{o h m, m}=\frac{I}{\sigma_{m}} l_{m},
\end{aligned}
$$

where $l_{g}$ and $l_{m}$ represent the thicknesses of the GDL and membrane, 
respectively. Cell voltage can be determined by the difference between the reversible cell voltage and fuel cell overpotentials:

$$
\begin{gathered}
V_{\text {cell }}=V_{\text {rev }}-\eta_{\text {act }}-\eta_{\text {ohm }, g}-\eta_{\text {ohm }, m}, \\
V_{\text {rev }}=V^{o}-\frac{R T}{2 \alpha F} \ln \left(\frac{a_{\mathrm{H}_{2} \mathrm{O}}}{a_{\mathrm{H}_{2}} a_{\mathrm{O}_{2}}^{0.5}}\right),
\end{gathered}
$$

\subsubsection{Boundary Conditions}

Fixed velocity boundary conditions were introduced to the cathode and anode inlet velocities of 0.3 and $0.2 \mathrm{~m} / \mathrm{s}$, respectively. Fixed pressure boundary conditions were applied to the outlets of the channel to simulate the operating pressure of the fuel cell. A symmetry boundary condition was applied to $y-z$ plane of the model. Isothermal conditions were applied to the walls of the $x-y$ plane. Combined Dirichlet and Neumann boundary conditions were used to solve for electronic and protonic potential equations. The geometric parameters and operating conditions used are given in Tables 1 and 2 .

\section{Numerical Method and Implementation}

We used commercial software COMSOL-Multiphysics, which uses Table 1 Geometric model parameters used in simulation

\begin{tabular}{cc}
\hline Cell temperature $(\mathrm{K})$ & $346.15^{16}$ \\
\hline Channel cross section $\left(\mathrm{mm}^{2}\right)$ & $2.5 \times 2.5^{16}$ \\
\hline Half bipolar plate cross section $\left(\mathrm{mm}^{2}\right)$ & $1.25 \times 1.25^{16}$ \\
\hline Cell length $(\mathrm{cm})$ & 5 \\
\hline GDL cross section $\left(\mu \mathrm{m}^{2}\right)$ & $10^{4} \times 500^{16}$ \\
\hline Catalyst layer cross section $\left(\mu \mathrm{m}^{2}\right)$ & $10^{4} \times 15^{16}$ \\
\hline Membrane cross section $\left(\mu \mathrm{m}^{2}\right)$ & $10^{4} \times 230^{16}$ \\
\hline Catalyst layer porosity & $0.32^{20}$ \\
\hline Membrane porosity & $0.3^{20}$ \\
\hline GDL permeability $\left(\mathrm{m}^{2}\right)$ & $1.18 \mathrm{E}-011^{20}$ \\
\hline Catalyst layer permeability $\left(\mathrm{m}^{2}\right)$ & $2.36 \mathrm{E}-012^{20}$ \\
\hline Membrane permeability $\left(\mathrm{m}^{2}\right)$ & $1 \mathrm{E}-018^{16}$ \\
\hline GDL electrical conductivity $(\mathrm{S} / \mathrm{m})$ & $222^{20}$ \\
\hline Membrane electrical conductivity $(\mathrm{S} / \mathrm{m})$ & $9.825^{20}$ \\
\hline
\end{tabular}

\begin{tabular}{|c|c|}
\hline Inlet mass fraction $\left(\mathrm{H}_{2} / \mathrm{O}_{2} / \mathrm{H}_{2} \mathrm{O}\right)$ & $0.73 / 0.228 / 0.023^{20}$ \\
\hline Anode-side inlet flow velocity $(\mathrm{m} / \mathrm{s})$ & $0.2^{16}$ \\
\hline Cathode-side inlet flow velocity $(\mathrm{m} / \mathrm{s})$ & $0.3^{16}$ \\
\hline Anode viscosity (Pa-s) & $1.19 \mathrm{E}-05^{20}$ \\
\hline Cathode viscosity (Pa-s) & $2.46 \mathrm{E}-05^{20}$ \\
\hline Molar mass $[\mathrm{kg} / \mathrm{mol}]\left(\mathrm{H}_{2} / \mathrm{N}_{2} / \mathrm{O}_{2} / \mathrm{H}_{2} \mathrm{O}\right)$ & $0.002 / 0.028 / 0.018 / 0.032$ \\
\hline $\mathrm{H}_{2}-\mathrm{H}_{2} \mathrm{O}$ binary diffusion coefficient $\left(\mathrm{m}^{2} / \mathrm{s}\right)$ & $1.12 \mathrm{E}-4^{21}$ \\
\hline $\mathrm{N}_{2}-\mathrm{H}_{2} \mathrm{O}$ binary diffusion coefficient $\left(\mathrm{m}^{2} / \mathrm{s}\right)$ & $3.15 \mathrm{E}-5^{21}$ \\
\hline $\mathrm{O}_{2}-\mathrm{N}_{2}$ binary diffusion coefficient $\left(\mathrm{m}^{2} / \mathrm{s}\right)$ & $2.94 \mathrm{E}-5^{21}$ \\
\hline $\mathrm{O}_{2}-\mathrm{H}_{2} \mathrm{O}$ binary diffusion coefficient $\left(\mathrm{m}^{2} / \mathrm{s}\right)$ & $3.45 \mathrm{E}-5^{21}$ \\
\hline Reference pressure $(\mathrm{Pa})$ & $101 \mathrm{E} 3^{20}$ \\
\hline Oxygen reference concentration $\left(\mathrm{mol} / \mathrm{m}^{3}\right)$ & $40.88^{20}$ \\
\hline Hydrogen reference concentration $\left(\mathrm{mol} / \mathrm{m}^{3}\right)$ & $40.88^{20}$ \\
\hline Anode ref. exchange current density $\left(\mathrm{A} / \mathrm{m}^{3}\right)$ & $9.22 \mathrm{E}+008^{16}$ \\
\hline Cathode ref. exchange current density $\left(\mathrm{A} / \mathrm{m}^{3}\right)$ & $1.05 \mathrm{E}+006^{16}$ \\
\hline Anode transfer coefficients $\left(\alpha_{\mathrm{a}}\right)$ & $1^{20}$ \\
\hline Cathode transfer coefficients $\left(\alpha_{\mathrm{c}}\right)$ & $1^{20}$ \\
\hline
\end{tabular}

Table 2 Mass transport and operating properties used in simulation the finite element method to solve equations. The multi-physics of flow, charge, heat and mass transfer in a PEMFC are coupled for steady-state simulation. The computational domain is discretized using mapped meshing with 125,000 domain elements, 42,800 boundary elements and 4000 edge elements. The present study makes use of a GDL composite porous layer in the PEMFC. This layer consists of two regions: a constant base porosity (i.e., under channel) region and a variable porosity (i.e., under land) region (Fig. 2). To compensate for the loss of porosity caused by solid boundary contact and external mechanical assembly pressure, the variable-porosity regions in the GDL are assigned with higher porosity (0.4 to 0.7$)$ than that of the constant-base-porosity region (0.4).

This study proposes a novel method of porosity variation in the GDL because the manufacturing process of such composite porous layers has not been reported yet. However, the literature suggests several methods to make non-uniform porosity in the GDL. The indirect methods include the use of gas diffusion barriers having a gas permeability gradient perpendicular to membrane of the fuel cell. ${ }^{22}$ Similarly the gas permeability which is closely related to porosity can be made non-uniform by using non-uniform pattern of perforations. ${ }^{23}$ The direct method includes variable porosity gas diffusion materials

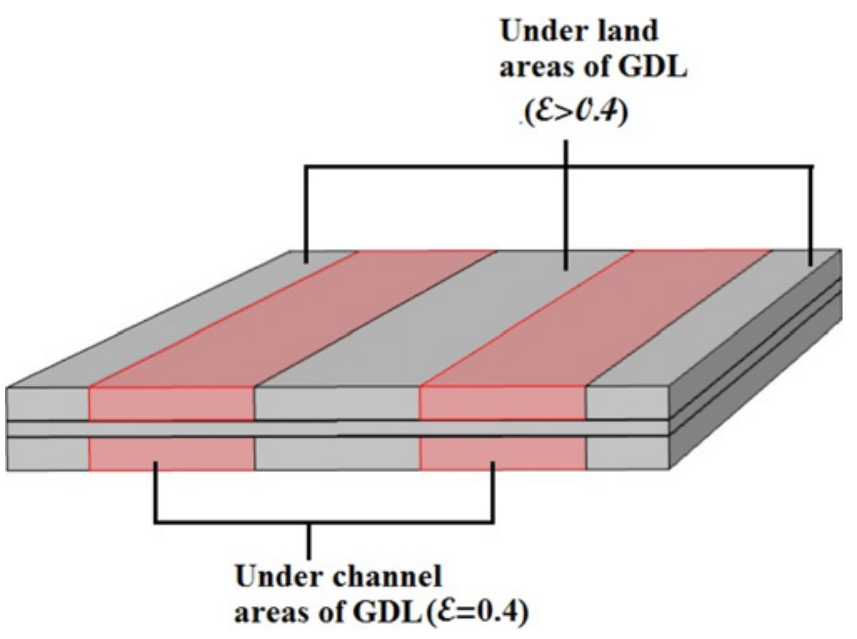

Fig. 2 Membrane electrode assembly with composite porous GDL

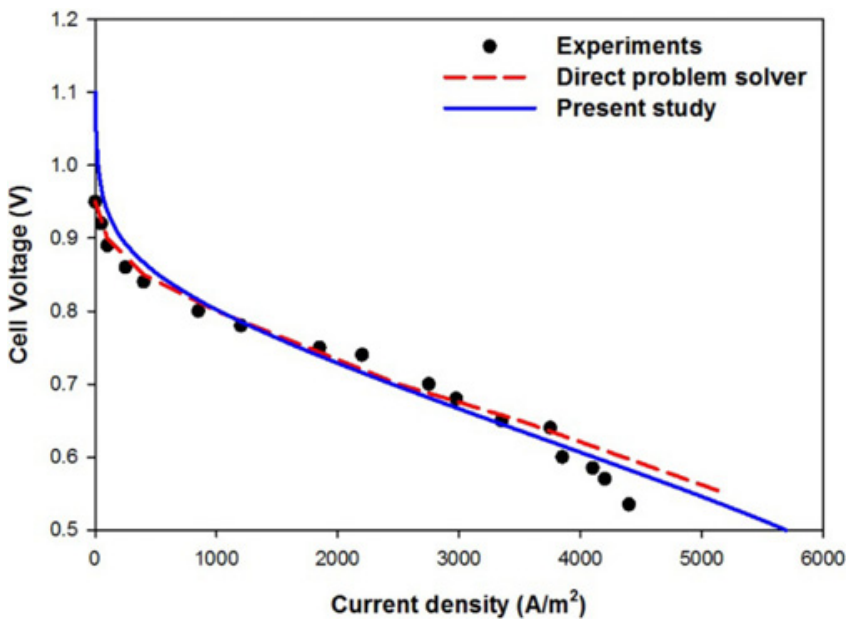

Fig. 3 Validation of computational model with experimental and numerical results of Cheng et al. ${ }^{20}$ 
used by Muthuswamy et al., in his fuel cell. ${ }^{24}$ Another important factor is the control of non-uniform porosity by means of maintaining the pore size, pore volume and surface area of porous material. The process is called Sol-gel process which controls the microstructures by particle packing technique, rate of condensation and the use of composite structures as reported by Brinker et al., and Antonietti et al.. ${ }^{25,26}$

Initially, the model is validated by plotting the polarization curve through the constant base porosity in the GDL. Two methods can be used to draw a polarization curve. In the first technique, cell voltage is specified as a boundary condition, and the solution is iterated to obtain the current and overpotential. The second approach assumes an average current density and computes the cell voltage. The former approach is more convenient than the latter and is thus used in this study. To compute the polarization curve, the overpotential values of PEMFC irreversibility have been calculated using equation (21), (22) and (23). The obtained polarization curve was compared with experimental and numerical results of Cheng et al., at the same temperature (Fig. 3). ${ }^{27}$ The obtained plot closely follows the experimental polarization profile until the current density of $4000 \mathrm{~A} / \mathrm{m} 2$, at which the latter drops because of decreased concentration of reactants. The plot is consistent with the cited numerical simulation and thus validates the model.

\section{Results and Discussion}

The effectiveness of using a composite porous GDL in the PEMFC is investigated by computing various parameters in steady-state simulation. The cathode side of a PEMFC is its most sensitive part, and attention has mainly been focused on computing the oxygen and water mass fraction in different orientations, in addition to the hydrogen mass fraction in the anode reaction site. Moreover, the overall performance of the cell is investigated with the proposed method with different GDL porosities under land and under channel areas by evaluating the polarization plots of the studied cases.

\subsection{Effects on Polarization Plots}

The overall performance of a PEMFC can be represented by a polarization plot between cell voltage and current density. Therefore, the present study investigates the performance of a composite porous GDL through polarization plots (Fig. 4). The plot shows a clear agreement for all the studied cases up to a moderate current density. However, the profiles deviate from the base case at high current densities. The initial agreement represents an equal amount of total polarization that includes activation, cross-over and Ohmic losses. Thus a modified porosity of the GDL does not affect the reaction rate and electrical resistance in the cell. On the other hand, the deviation in the plot with increased current density shows an increase in reactant concentrations because concentration polarization has been limited. This means that porosity increase in only under land areas of the GDL increases the current density of the PEMFC.

The difference in current density magnitude for specific voltage is not so significant, thus a local current density distribution needs to be investigated. The presence of liquid water in the cell may also contribute to reduce the cell performance for the base porosity case by blocking the pores in the GDL. The reference exchange current density and Ohmic resistance of the cell are the other factors responsible for the lower fuel cell performance in the uniform porosity case. However, Roshendel et al. reported that it is the reduced pore size and the effective porosity with larger contribution in the cell overpotential. ${ }^{5}$ Therefore, a composite porous GDL also increases the overall performance of the PEMFC by increasing the mass transport of the reactant species to the reaction sites in addition to compensating for the loss of porosity.

A more prominent way to describe the fuel cell performance is the investigation of local current density distribution on the fuel cell electrode surface. For this purpose, anode side local current density was evaluated at mid length of the cell for the four cases at a cell voltage of $0.45 \mathrm{~V}$ as shown in Fig. 5. The plot shows that the increase in porosity under land areas significantly improves the current density in those regions. The gradient in current density gets reduced with the porosity increase and the trend shows that it may become nearly constant for a further porosity increase. Thus, it can be inferred that an increase in porosity under land areas of the bipolar plate may also help in making a uniform current density distribution.

\subsection{Effects on Cathode Reaction Site}

In a PEMFC, oxygen is transported into the catalyst layer through the GDL to complete the fuel cell reaction and produce water. The

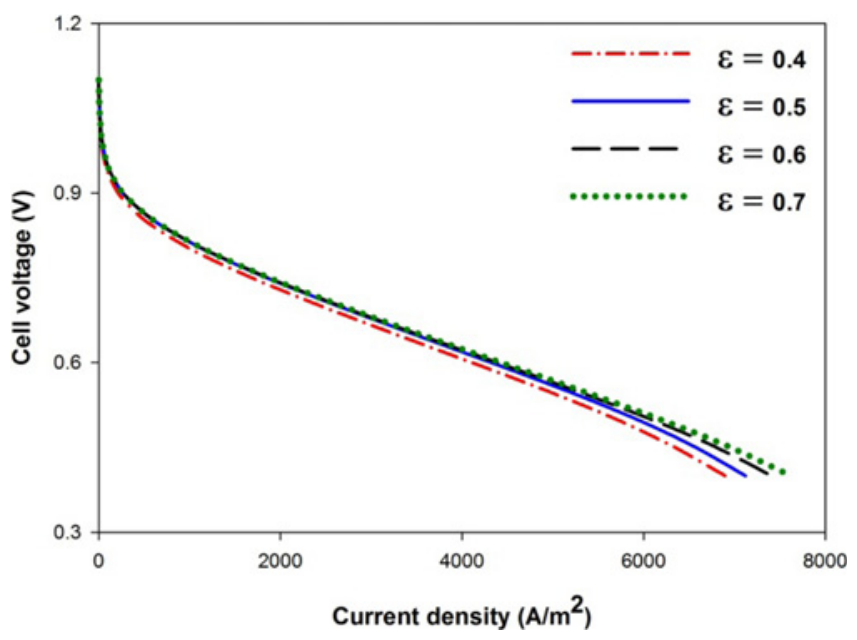

Fig. 4 Computed polarization plot for various composite porous GDLs

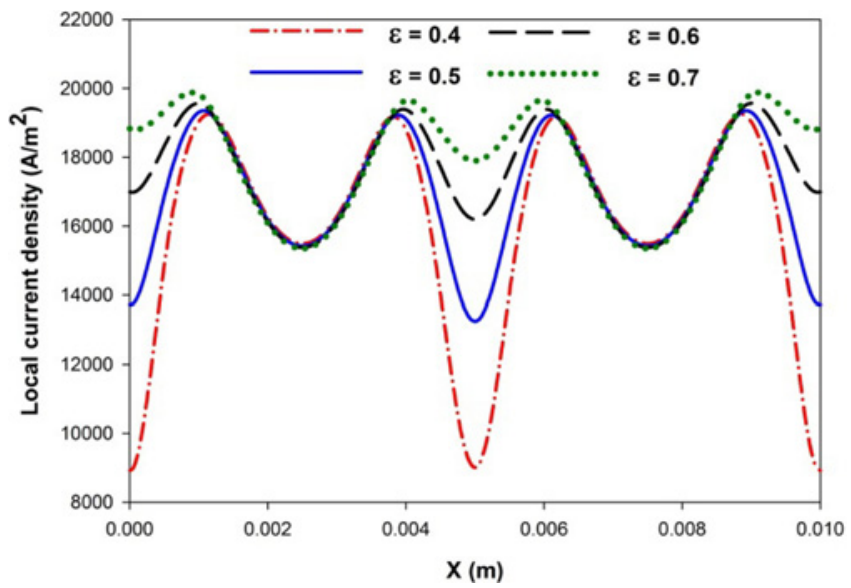

Fig. 5 Anode side local current density distribution for various composite porous GDLs 
cathode side is highly sensitive to the production of electricity depending on the effective transport of oxygen. Therefore, we mainly focused on the oxygen consumption and water production at the catalyst GDL interface with various combinations of composite porous GDL layers.

Fig. 6(a) represents the computed oxygen mass fractions that reach the cathodic reaction site along the channel. The effect of composite porosity is incorporated by plotting the oxygen consumption at the junction of the under-land and under-channel regions. The plot represents the initial rapid consumption of oxygen near the channel inlet; oxygen consumption later stabilizes along the cell length. This initial drop in the oxygen mass fraction is dominated by the high inlet velocity of the reactant mixture; all the cases exhibit this behavior. The effect of high porosity under land areas is significant with moderate velocities in the middle of the channel, where oxygen consumption increases when porosity is high. The amount of oxygen consumption increases with increased porosity in the under-land areas of the GDL. These effects are also verified by the water mass fraction at the same location (Fig. 6(b)). The increase in water mass fraction along the cell length represents an improved cathodic reaction with high porosity in the under-land areas of the GDL.

In the composite porous layer, the porosity variation was made across the length of the cell. Therefore, the evaluation of the reactants and products transport across the GDL was made at the mid length. At
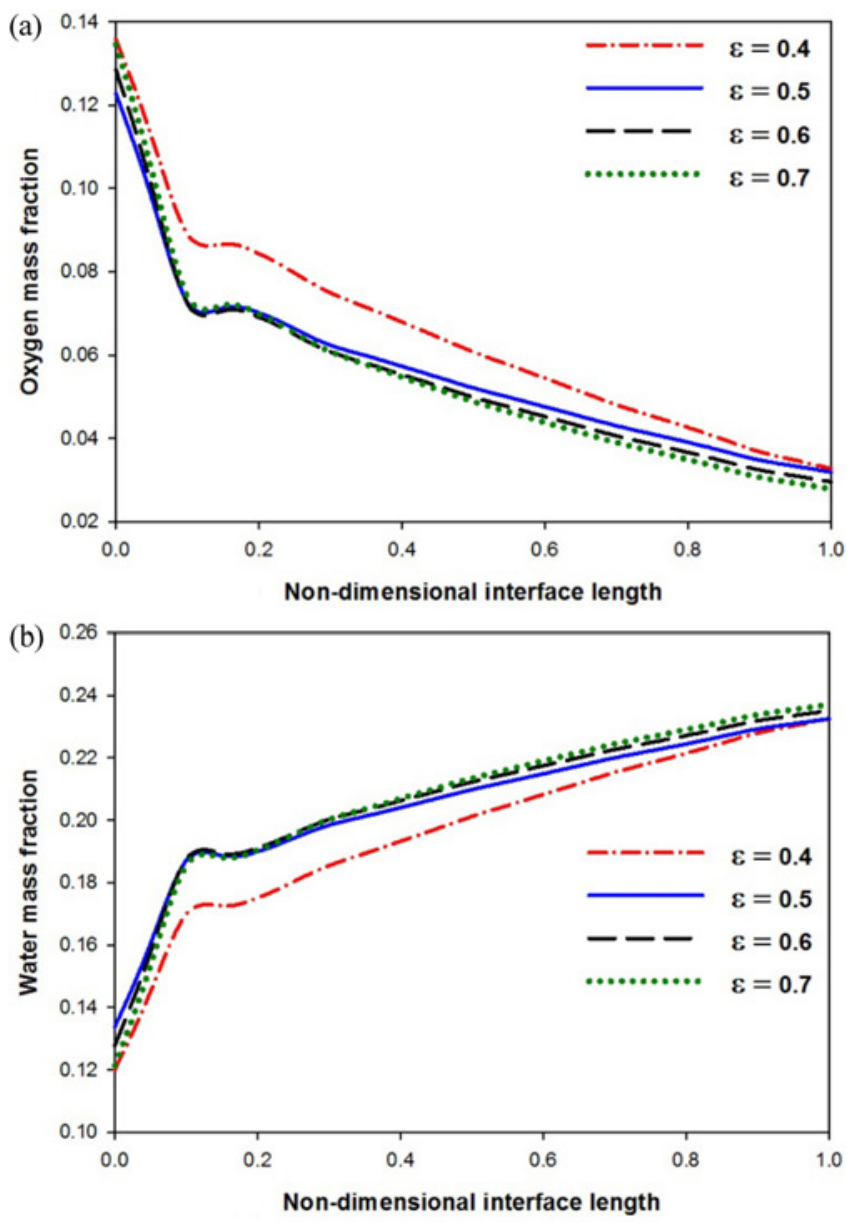

Fig. 6 Effect of composite porous GDL on cathode reaction site: (a) oxygen mass fraction and (b) water mass fraction along cell length the catalyst GDL interface, the oxygen consumption increases only under land areas of the GDL having higher porosity when moving across the cell length as shown in Fig. 7(a). No significant difference is found in the oxygen mass fraction values under the channel areas. The water at the catalyst GDL interface is similarly affected (Fig. 7(b)). The variation in horizontal porosity is mainly responsible for the formation of these mass fraction patterns.

\subsection{Effects on Anode Reaction Site}

The anodic reaction site is equally important in fuel cell operation because the reaction is initiated at this location. Therefore, the mass transport of hydrogen is also investigated at the catalyst GDL interface of the anode side. The results present a significant difference between the studied cases, with similar patterns found at the cathode reaction site. An interesting feature is observed in Fig. 8(a) and 8(b) that represent the effect of difference in porosity value of under land and under channel areas of GDL. This pattern contrasts with that in the cathodic reaction site, where mass transport properties gradually improve. At the anode reaction site, a small difference in the porosity of two distinct regions increases the reactant mass fraction.

These results imply that the use of a composite GDL porous layer improves the consumption of reactants (e.g., $\mathrm{H}_{2}$ and $\mathrm{O}_{2}$ ) and increases the amount of products (e.g., $\mathrm{H}_{2} \mathrm{O}$ ). However, the produced water must remain in vapor form and therefore depends on cell temperature. A
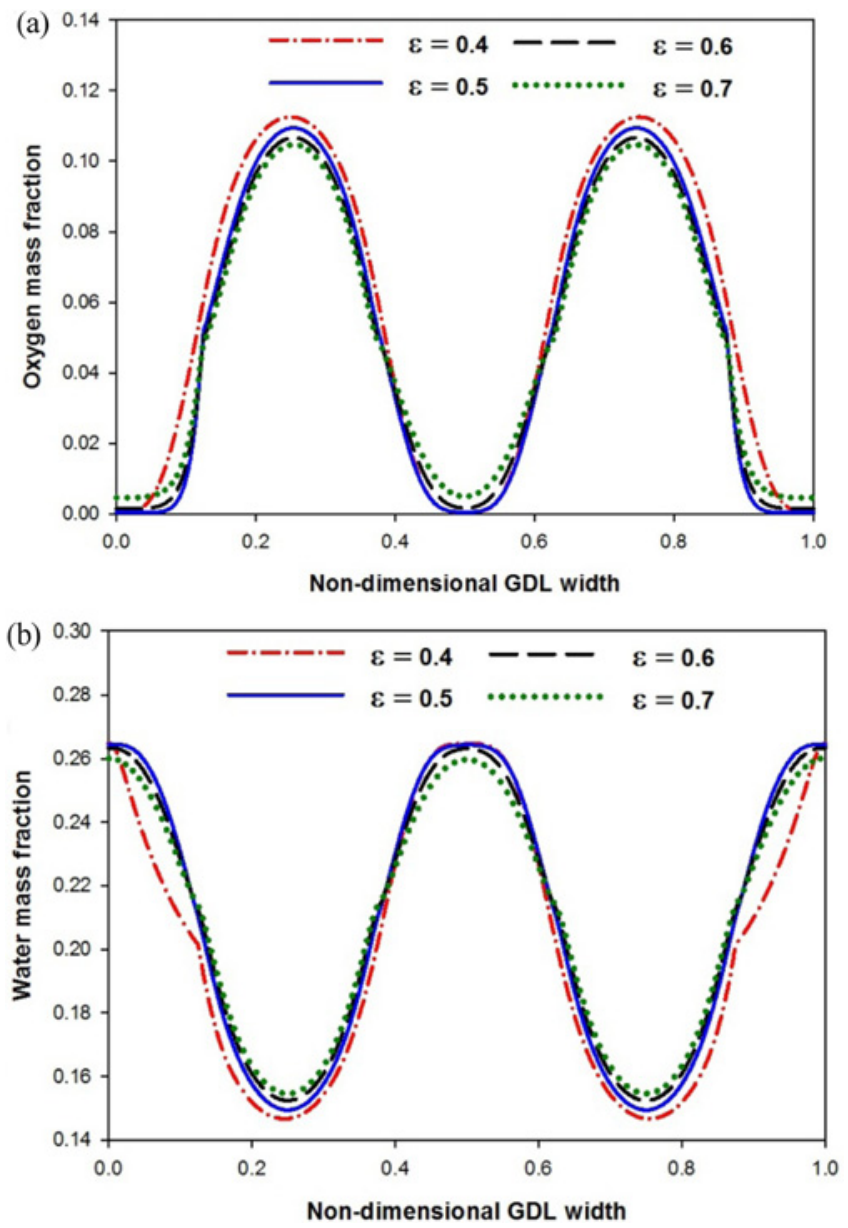

Fig. 7 Effect of composite porous GDL at mid-length of cathode reaction site: (a) oxygen mass fraction and (b) water mass fraction across cell length 
unique feature observed in all the cases discussed here is the importance of using non-uniform GDL porosity. The mass fraction trends are similar in all the cases; however, a significant difference in magnitude exists between the uniform and non-uniform porosity cases as shown in Fig. 6 and Fig. 8. The gas flow momentum generated by the large pores due to increase in porosity under land areas helps in improving the mass transport in the under channel areas as well. It means that a composite porous layer with non-uniform porosity improves overall mass transfer by only increasing the porosity of the GDL under land areas. Therefore, mass transport is strongly influenced by the pattern of porosity variation in the GDL. The introduction of the composite GDL porous layer improves the transport of species not only in the under-land areas of the GDL but also in its under-channel areas. Therefore, this layer affects the overall performance of the fuel cell.

\section{Conclusions}

This study is carried out to numerically investigate the effects of introducing a composite porous GDL to a PEMFC. The composite porous GDL uses a positional variation method that enhances flow and mass transfer properties by utilizing higher porosity in under-land areas than that in under-channel areas to counter the effects of reduced porosity and thus improve overall PEMFC performance. The
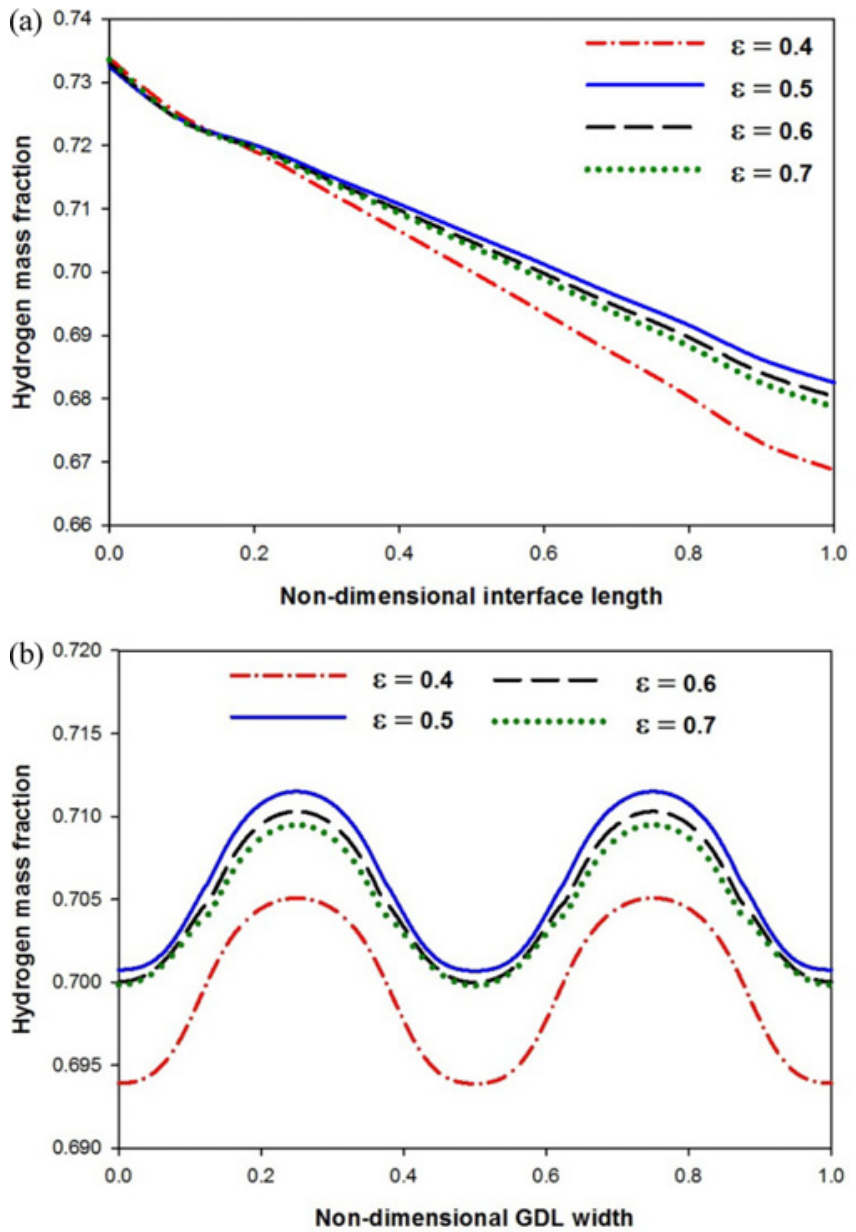

Fig. 8 Effect of composite porous GDL on anode reaction site: hydrogen mass fractions (a) along cell length and (b) across cell length investigation is performed by computing the oxygen and water mass fractions in different orientations at the cathode reaction sites in addition to the hydrogen mass fraction in the anode reaction site. Moreover, the overall performance of the cell is examined with the proposed porosity variation method by evaluating the polarization plots of the studied cases.

The results show the effectiveness of the proposed composite porous GDL with improved PEMFC performance because the transport of the reactant species to and from the reaction sites is enhanced. Mass transport is strongly influenced by the pattern of porosity variation in the GDL. The introduction of the composite porous GDL improves the transport of species not only in the under-land areas of the GDL but also in its under-channel areas, thus affecting the overall performance of the fuel cell. PEMFC performance can further be improved with an optimized catalyst loading based on the composite porosity of the GDL. Such optimization will reduce the operating cost of the fuel cell with a uniform current density.

\section{ACKNOWLEDGMENT}

This work was supported by a National Research Foundation (NRF) of Korea grant funded by the Korea Government (MEST) (No. 2012R1A2A2A01046099), and a grant from the Priority Research Centers Program through the National Research Foundation of Korea (NRF) funded by MEST (2012-0005856).

\section{REFERENCES}

1. Mathias, M., Roth, J., Fleming, J., and Lehnert, W., "Handbook of Fuel Cells Fundamentals, Technology and Applications," John Wiley \& Sons, pp. 517-537, 2003.

2. Gurau, V., Barbir, F., and Liu, H., "An Analytical Solution of a Half - Cell Model for PEM Fuel Cells," Journal of the Electrochemical Society, Vol. 147, No. 7, pp. 2468-2477, 2000.

3. Bernardi, D. M. and Verbrugge, M. W., "A Mathematical Model of the Solid Polymer Electrolyte Fuel Cell," Journal of the Electrochemical Society, Vol. 139, No. 9, pp. 2477-2491, 1992.

4. Broka, K. and Ekdunge, P., "Modelling the PEM Fuel Cell Cathode," Journal of Applied Electrochemistry, Vol. 27, No. 3, pp. 281-289, 1997.

5. Roshandel, R. and Farhanieh, B., "The Effects of Non-Uniform Distribution of Catalyst Loading on Polymer Electrolyte Membrane Fuel Cell Performance,” International Journal of Hydrogen Energy, Vol. 32, No. 17, pp. 4424-4437, 2007.

6. Park, S. B. and Park, Y. I., "Fabrication of Gas Diffusion Layer Containing Micro Porous Layer using Fluorinated Ethylene Prophylene for Proton Exchange Membrane Fuel Cell," Int. J. Precis. Eng. Manuf., Vol. 13, No. 7, pp. 1145-1151, 2012.

7. Lee, W.-K., Ho, C.-H., Van Zee, J., and Murthy, M., "The Effects of Compression and Gas Diffusion Layers on the Performance of a 
PEM Fuel Cell,” Journal of Power Sources, Vol. 84, No. 1, pp. 4551, 1999.

8. Ge, J., Higier, A., and Liu, H., "Effect of Gas Diffusion Layer Compression on PEM Fuel Cell Performance," Journal of Power Sources, Vol. 159, No. 2, pp. 922-927, 2006.

9. Lin, J.-H., Chen, W.-H., Su, Y.-J., and Ko, T.-H., "Effect of Gas Diffusion Layer Compression on the Performance in a Proton Exchange Membrane Fuel Cell," Fuel, Vol. 87, No. 12, pp. 24202424, 2008.

10. Rowe, A. and Li, X., "Mathematical Modeling of Proton Exchange Membrane Fuel Cells," Journal of Power Sources, Vol. 102, No. 1, pp. 82-96, 2001.

11. Dutta, S., Shimpalee, S., and Van Zee, J., "Numerical Prediction of Mass-Exchange between Cathode and Anode Channels in a PEM Fuel Cell," International Journal of Heat and Mass Transfer, Vol. 44, No. 11, pp. 2029-2042, 2001.

12. Thampan, T., Malhotra, S., Zhang, J., and Datta, R., "PEM Fuel Cell as a Membrane Reactor," Catalysis Today, Vol. 67, No. 1, pp. 15-32, 2001.

13. Chu, H.-S., Yeh, C., and Chen, F., "Effects of Porosity Change of Gas Diffuser on Performance of Proton Exchange Membrane Fuel Cell,” Journal of Power Sources, Vol. 123, No. 1, pp. 1-9, 2003.

14. Roshandel, R., Farhanieh, B., and Saievar-Iranizad, E., "The Effects of Porosity Distribution Variation on PEM Fuel Cell Performance," Renewable Energy, Vol. 30, No. 10, pp. 1557-1572, 2005.

15. Stockie, J. M., Promislow, K., and Wetton, B. R., "A Finite Volume Method for Multicomponent Gas Transport in a Porous Fuel Cell Electrode," International Journal for Numerical Methods in Fluids, Vol. 41, No. 6, pp. 577-599, 2003.

16. Cheema, T. A., Zaidi, S., and Rahman, S., "Three Dimensional Numerical Investigations for the Effects of Gas Diffusion Layer on PEM Fuel Cell Performance," Renewable Energy, Vol. 36, No. 2, pp. 529-535, 2011.

17. Brinkman, H. C., "A Calculation of the Viscous Force Exerted by a Flowing Fluid on a Dense Swarm of Particles," Applied Scientific Research, Vol. 1, No. 1, pp. 27-34, 1949.

18. Taylor, R. and Krishna, R., "Multicomponent Mass Transfer," Wiley, New York, 1993.

19. Springer, T. E., Zawodzinski, T., and Gottesfeld, S., "Polymer Electrolyte Fuel Cell Model," Journal of The Electrochemical Society, Vol. 138, No. 8, pp. 2334-2342, 1991.

20. Ubong, E., Shi, Z., and Wang, X., "Three-Dimensional Modeling and Experimental Study of a High Temperature PBI-based PEM Fuel Cell," Journal of The Electrochemical Society, Vol. 156, No. 10, pp. B1276-B1282, 2009.

21. Cussler E. L., "Diffusion-Mass Transfer in Fluid Systems," Cambridge University Press, London, $3^{\text {rd }}$ Ed., pp. 119-120, 2009.
22. Koschany, A., Lucas, C., and Schwesinger, T., "Gas Diffusion Electrode with Reduced Diffusing Capacity for Water and Polymer Electrolyte Membrane Fuel Cells," US Patent, No. 6451470, 2002.

23. Mossman, A. and Gallagher, E. R., "Electrochemical Fuel Cell with Fluid Distribution Layer Having Non-Uniform Permeability," EP Patent, No. 1639668 B1, 2008.

24. Muthuswamy, S., Pratt, S. D., Kelley, R. J., and Kim, G., "Fuel Cell Using Variable Porosity Gas Diffusion Material," US Patent, No. 71321192 B2, 2006.

25. Brinker, C., Sehgal, R., Hietala, S., Deshpande, R., Smith, D., et al., "Sol-Gel Strategies for Controlled Porosity Inorganic Materials," Journal of Membrane Science, Vol. 94, No. 1, pp. 85-102, 1994.

26. Antonietti, M., Fechler, N., and Fellinger T. P., "Carbon Aerogels and Monoliths: Control of Porosity and Nanoarchitecture via SolGel Routes," Chemistry of Material, Vol. 26, No. 1, pp. 196-210, 2014.

27. Cheng, C. H., Lin, H. H., and Lain, G. J., "Design for Geometric Parameters of PEM Fuel Cell by Integrating Computational Fluid Dynamics Code with Optimization Method," Journal of Power Sources, Vol. 165, No. 2, pp. 803-813, 2007. 